\title{
The Rhizobium leguminosarum bv. viciae VF39 $\gamma$-aminobutyrate (GABA) aminotransferase gene (gabT) is induced by GABA and highly expressed in bacteroids
}

\author{
Jürgen Prell, ${ }^{1}$ Bert Boesten, ${ }^{1}$ Philip Poole ${ }^{2}$ and Ursula B. Priefer ${ }^{1}$
}

Author for correspondence: Jürgen Prell. Tel: +49 241 8026647. Fax: +49 2418022637. e-mail: prell@bio1.rwth-aachen.de

1 Ökologie des Bodens, Botanisches Institut, RWTH-Aachen, Worringerweg 1, 52056 Aachen, Germany

2 Division of Microbiology, School of AMS, University of Reading, Whiteknights, Reading RG6 6AJ, UK

\begin{abstract}
A Rhizobium leguminosarum bv. viciae VF39 gene (gabT) encoding a $\gamma$ aminobutyrate (GABA) aminotransferase was identified, cloned and characterized. This gene is thought to be involved in GABA metabolism via the GABA shunt pathway, a theoretical bypass of the 2-oxoglutarate dehydrogenase complex. Mutants in gabT are still able to grow on GABA as a sole carbon and nitrogen source. 2-0xoglutarate-dependent GABA aminotransferase activity is absent in these mutants, while pyruvatedependent activity remains unaffected. This indicates that at least two enzymes with different substrate specifities are involved in the GABA metabolism of $R$. leguminosarum bv. viciae VF39. The gabT promoter was cloned into a newly constructed, stable promoter-probe vector $\mathrm{pJP2}$, suitable for the study of transcriptional GUS fusions in free-living bacteria and during symbiosis. Under free-living conditions the gabT promoter is induced by GABA and repressed by succinate. Transcriptional regulation is mediated by GabR in a repressor-like manner. During symbiosis with the pea host plant gabT is induced and highly expressed in the symbiotic zone. Nodules induced by gabT mutants, however, are still effective in nitrogen fixation.
\end{abstract}

Keywords: carbon metabolism, GABA shunt, symbiotic expression, promoter-probe vector, pJP2

\section{INTRODUCTION}

During symbiosis between Rhizobium spp. and the legume host plant, the bacteria are released into a new environment, the plant cell, in which they differentiate into nitrogen-fixing bacteroids. The bacteroids remain enclosed in a plant-derived peribacteroid membrane, which constitutes a selective barrier between the microsymbiont and the plant cytosol. Nutrient exchange between the symbiotic partners takes place across this barrier.

$\mathrm{C}_{4}$-dicarboxylic acids are thought to be the only source of carbon skeletons available to the bacteroids in

Abbreviations: GABA, $\gamma$-aminobutyrate; GUS, $\beta$-D-glucuronidase; PEP, phosphoenolpyruvate; PNP, $p$-nitrophenol; SSDH, succinate semialdehyde dehydrogenase; TCA, tricarboxylic acid; X-Gal, 5-bromo-4-chloro-3-indolyl $\beta$-D-galactopyranoside; X-Glc, 5-bromo-4-chloro-3-indolyl $\beta$-D-glucuronic acid.

The GenBank accession number for the sequence determined in this work is AF335502. sufficient amounts to support the energetically expensive process of nitrogen fixation. These dicarboxylic acids are derived from the plant's glycolysis. Phosphoenolpyruvate (PEP) is carboxylated via PEP carboxylase (EC 4.1.1.31) to oxaloacetate and then further reduced by malate dehydrogenase (EC 1.1.1.37) to malate (Streeter, 1991; Vance \& Heichel, 1991). The $\mathrm{C}_{4}$-dicarboxylic acids are taken up by the bacteroids and presumably directly channelled into the TCA cycle. Atmospheric nitrogen is fixed to ammonia by the nitrogenase enzyme complex, which is expressed in the bacteroids in response to the low oxygen concentration present in the nodule. The majority of the ammonia produced is transported to the plant host cell, where it is assimilated and incorporated into amino acids. Part of the ammonia however appears to be assimilated by the bacteroids themselves in order to maintain their metabolism. Two potential ammonia-assimilating enzymes, alanine dehydrogenase (EC 1.4.1.1) and glutamate dehydrogenase (EC 1.4.1.2) both show high activities in mature bacteroids of Sinorhizobium meliloti (Miller et al., 
1991). Alanine is, as recently discovered, also an excretion product of anaerobically isolated mature bacteroids in soybean and pea (Waters et al., 1998; Allaway et al., 2000).

The role of glutamate, which generally appears in large quantities in the nodules (Miller et al., 1991; Vance \& Heichel, 1991; Salminen \& Streeter, 1992), remains unclear. A reason for glutamate accumulation could be the inhibition of the bacterial 2-oxoglutarate dehydrogenase complex during symbiosis. This complex is part of the TCA cycle and converts 2-oxoglutarate to succinyl-CoA. It is sensitive to the redox charge of the cell because of inhibition by the concentration of NADH (Streeter, 1991). The high NADH level in bacteroids is probably due to oxygen limitation, which is also a prerequisite for effective functioning of the bacteroids' nitrogenase (McDermott et al., 1989; Dunn, 1998; Poole \& Allaway, 2000). In symbiosis, 2-oxoglutarate could be directly aminated by glutamate dehydrogenase, or transaminated by any aminotransferase using 2-oxoglutarate as the receiving oxoacid. Consistent with this, mutations in the 2-oxoglutarate dehydrogenase complex in Rhizobium leguminosarum bv. viciae 3841 lead to the synthesis and excretion of large quantities of glutamate (Walshaw et al., 1997).

A possible sink for glutamate in bacteroids includes the GABA shunt pathway. This is a theoretical bypass of the 2-oxoglutarate dehydrogenase complex, in which glutamate is decarboxylated to $\gamma$-aminobutyric acid (4aminobutyrate; GABA) by glutamate decarboxylase (EC 4.1.1.15). The amino residue of GABA is removed by GABA aminotransferase (EC 2.6.1.19) leading to succinate semialdehyde, which is further oxidized to succinate by succinate-semialdehyde dehydrogenase (EC 1.2.1.16). The GABA aminotransferase is a pyridoxalphosphate-dependent enzyme that transfers the amino residue of GABA to an oxoacid. In the case of 2oxoglutarate as the receiving oxoacid, this reaction would also cover the first step of the pathway, the amination of 2-oxoglutarate to glutamate. The existence of a GABA shunt pathway in Rhizobium spp. has been often discussed (McDermott et al., 1989; Miller et al., 1991; Dunn, 1998; Poole \& Allaway, 2000). However, it has never been confirmed to operate during symbiosis, as corresponding mutants were not available.

In this paper, we report the identification, cloning and analysis of the R. leguminosarum bv. viciae VF39 gabT gene, encoding 2-oxoglutarate-dependent GABA aminotransferase. We constructed mutants and analysed gabT expression in free-living state and in bacteroids. We show that while GabT is not essential for growth on GABA or symbiotic nitrogen fixation, it is specifically induced in the nodule, suggesting a role in bacteroid metabolism.

\section{METHODS}

Bacterial strains, plasmids and media. All bacterial strains and plasmids used in this work are listed in Table 1.
Escherichia coli strains were grown at $37^{\circ} \mathrm{C}$ in Luria-Bertani medium (Maniatis et al., 1982). Rhizobium leguminosarum strains were grown at $29^{\circ} \mathrm{C}$ in TY complex medium (Beringer, 1974), Vincent minimal medium (VMM) (Vincent, 1970) or acid minimal salt medium (AMS) (Poole et al., 1994), supplemented with $0 \cdot 2 \%(\mathrm{w} / \mathrm{v})$ GABA or glutamate as carbon and nitrogen source. $\mathrm{NH}_{4} \mathrm{Cl}(0 \cdot 1 \%, \mathrm{w} / \mathrm{v})$ was added as nitrogen supply when succinate was given as carbon source.

To adjust the $\mathrm{pH}$, TY media were buffered with $50 \mathrm{mM}$ MES (for $\mathrm{pH} 5.3$ and 6.0 ), with $50 \mathrm{mM}$ MOPS (pH 7.0) or with $50 \mathrm{mM}$ TABS $(\mathrm{pH} 8 \cdot 0)$. 5-Bromo-4-chloro-3-indolyl $\beta$-Dgalactopyranoside (X-Gal) was added at a final concentration of $40 \mu \mathrm{g} \mathrm{ml} l^{-1}$.

For $\beta$-D-glucuronidase (GUS) activity, TY solid media were supplemented with 5-bromo-4-chloro-3-indolyl $\beta$-D-glucuronic acid (X-Glc) at a final concentration of $40 \mu \mathrm{g} \mathrm{ml}^{-1}$.

Antibiotics were used as needed for E. coli strains at the following final concentrations: ampicillin $100 \mu \mathrm{g} \mathrm{m}^{-1}$; kanamycin $25 \mu \mathrm{g} \mathrm{ml}^{-1}$; tetracycline $10 \mu \mathrm{g} \mathrm{ml}^{-1}$. For R. leguminosarum, antibiotics were added at final concentrations of: $500 \mu \mathrm{g} \mathrm{ml}^{-1}$ (streptomycin); $80 \mu \mathrm{g} \mathrm{ml}^{-1}$ (neomycin) and $10 \mu \mathrm{g} \mathrm{ml}^{-1}$ (tetracycline).

Preparation of cell extracts. Cultures of $R$. leguminosarum VF39 WT or mutant strains were grown overnight on AMS $(400 \mathrm{ml})$ or VMM $(250 \mathrm{ml})$, supplemented with GABA and glutamate and were harvested at an $\mathrm{OD}_{600}$ of approximately 0.5 by centrifugation $\left(8000\right.$ r.p.m.; $10 \mathrm{~min} ; 4^{\circ} \mathrm{C}$; Sorvall SLA3000). The pellet was suspended in $50 \mathrm{ml} 20 \mathrm{mM}$ phosphate buffer ( $\mathrm{pH} 7 \cdot 2)$ and centrifuged again. Then the cells were resuspended in 4-8 $\mathrm{ml}$ breaking buffer $(40 \mathrm{mM}$ HEPES, $1 \mathrm{mM}$ DTT at $\mathrm{pH} 7 \cdot 0$ ) and either crushed twice in a French pressure cell at $70 \mathrm{MPa}$ or sonicated for $3 \mathrm{~min}$ at $90 \mathrm{~W}$ on ice. Cell debris was removed by centrifugation (17000 r.p.m.; $25 \mathrm{~min} ; 4^{\circ} \mathrm{C}$; Sorvall SS34). The cell extracts were kept on ice and enzyme activities were measured within $2 \mathrm{~h}$ after preparation. Protein concentrations were determined by the method of Bradford (1976) and compared to a BSA standard $\left(0-20 \mu \mathrm{g} \mathrm{ml}^{-1}\right)$. Protein concentrations in the prepared cell extracts were between 1 and $3 \mathrm{mg} \mathrm{ml}^{-1}$.

Enzyme assays. 2-Oxoglutarate-dependent GABA aminotransferase was measured with $150 \mathrm{mM}$ GABA and $50 \mathrm{mM} 2$ oxoglutarate (disodium salt) as substrates, as earlier described by Bartsch (1990). The assay was performed in a final volume of $500 \mu \mathrm{l}$, using $250 \mu \mathrm{l}$ cell extract. Glutamate formation was determined by reduction of $\mathrm{NAD}^{+}$in a coupled glutamate dehydrogenase $(\mathrm{GDH})$ assay. In a final volume of $1.5 \mathrm{ml}$ [40 mM hydrazine; $50 \mathrm{mM}$ glycine ( $\mathrm{pH} 7.6) ; 2.7 \mathrm{mM} \mathrm{NAD}^{+}$; 3 units GDH (Sigma, G-2626)], the complete GABA aminotransferase sample $(500 \mu \mathrm{l})$ was incubated for $1.5 \mathrm{~h}$ at $37^{\circ} \mathrm{C}$. NADH production was measured at $340 \mathrm{~nm}$ in a spectrophotometer. Assays were done in duplicate with a "minus enzyme' control for each extract. Results were compared to a standard curve (with $0-120 \mathrm{nmol}$ glutamate per sample in duplicate), prepared freshly every day.

Pyruvate-dependent GABA aminotransferase activity was measured with $150 \mathrm{mM} \mathrm{GABA}$ and $50 \mathrm{mM}$ pyruvate (sodium salt) as substrates. The assay was performed as described for 2-oxoglutarate-dependent GABA aminotransferase with the following changes. Ten microlitres of cell extract was used in a final assay volume of $500 \mu \mathrm{l}$. Alanine production was measured in a final volume of $1.5 \mathrm{ml} \quad[40 \mathrm{mM}$ hydrazine; $50 \mathrm{mM}$ glycine ( $\mathrm{pH} 9 \cdot 0) ; 2.7 \mathrm{mMNAD}^{+} ; 0.5$ units alanine dehydrogenase (Sigma, A-7653)]. 
Table 1. Bacterial strains and plasmids

\begin{tabular}{|c|c|c|}
\hline Strain or plasmid & Description & Reference \\
\hline \multicolumn{3}{|l|}{ Bacteria } \\
\hline S17-1 & E. coli $294::[\mathrm{RP} 4-2(\mathrm{Tc}:: \mathrm{Mu})(\mathrm{Km}:: \mathrm{Tn} 7)]$ pro res $\Delta \operatorname{rec} \mathrm{A}, \mathrm{Tp}^{\mathrm{r}}$ & Simon et al. (1983) \\
\hline VF39 & R. leguminosarum bv. viciae wild-type, $\mathrm{Sm}^{\mathrm{r}}$ & Priefer (1989) \\
\hline VF39-TP2 & VF39 $\Delta l a c Z, \mathrm{Sm}^{\mathrm{r}} \mathrm{Tc}^{\mathrm{r}}$ & T. Patchkowski, RWTH-Aachen \\
\hline PH10 & VF39-TP2, gabT::Tn5-B20 & V. Lipka, RWTH-Aachen \\
\hline VF39-19T & pK19mob gabT plasmid integration mutant & This work \\
\hline VF39-18R & pK18mob gabR plasmid integration mutant & This work \\
\hline \multicolumn{3}{|l|}{ Plasmids } \\
\hline pWKR102A & $m o b, \mathrm{Gm}^{\mathrm{r}} \mathrm{Cm}^{\mathrm{r}}$ & Colonna-Romano et al. (1990) \\
\hline pWKR102A : : Tn5-B20/8 & pWKR102::Tn5-B20 & V. Lipka, RWTH-Aachen \\
\hline pSVB28 & pUC8 derivative with new polylinker region, $\mathrm{Ap}^{\mathrm{r}}$ & Arnold \& Pühler (1988) \\
\hline pSVB28-PH10SalI & pSVB28 with $10 \cdot 7 \mathrm{~kb}$ Sall fragment gabT: :Tn5-B20 & This work \\
\hline pTR102 & Mini-RK2, $A p^{r} T c^{r}$ & Weinstein et al. (1992) \\
\hline pTR102-d & Deletion of pTR102, $\mathrm{Ap}^{\mathrm{r}} \mathrm{Tc}^{\mathrm{r}}$ & This work \\
\hline pCCOGUS & pUC19 derivative with a promoterless GUS cartridge, $A p^{r}$ & Axelos et al. (1989) \\
\hline pTR102-GUS & pTR102-d with promoterless GUS cartridge, $\mathrm{Ap}^{\mathrm{r}} \mathrm{Tc}^{\mathrm{r}}$ & This work \\
\hline $\mathrm{pJP2}$ & pTR102 GUS with artificial MCS, $\operatorname{Ap}^{r} \operatorname{Tc}^{r}$ & This work \\
\hline $\mathrm{pJP} 2-g a b T$ & pJP2 with a $572 \mathrm{bp}$ fragment containing the gabT promoter & This work \\
\hline pK18/19mob & pK18/19 derivatives, $m o b, \mathrm{Km}^{\mathrm{r}}$ & Schäfer et al. (1994) \\
\hline pK19mob-gabT & pK19mob with a 394 bp Ecl136II/EcoRI gabT fragment & This work \\
\hline pK18mob-gabR & pK18mob with a 392 bp SalI/HindIII gabR fragment & This work \\
\hline
\end{tabular}

Succinate-semialdehyde dehydrogenase (SSDH) was measured with $2.5 \mathrm{mM}$ succinate semialdehyde and $1 \mathrm{mM} \mathrm{NAD}^{+}$as substrates (Laura Green, University of Missouri, personal communication). The assay was performed in $50 \mathrm{mM}$ Tris buffer at $\mathrm{pH} 8 \cdot 0,1 \mathrm{mM}$ DTT and $10 \mathrm{mM} \mathrm{KCN}$, to avoid reoxidation of NADH by cytochrome $c$ oxidase. Reduction of $\mathrm{NAD}^{+}$was measured spectrophotometrically at $340 \mathrm{~nm}$.

GUS and lacZ activity assays. Precultures grown on TY medium were harvested and transferred to VMM containing the different substrates. The cultures were started at an $\mathrm{OD}_{600}$ of 0.2 and showed a basic level of induction of about $100 \mathrm{nmol}$ $p$-nitrophenol (PNP) $\min ^{-1}$ per $\mathrm{OD}_{600}$ unit (Fig. $\left.3, t=0\right)$. GUS was assayed as previously described by Boesten et al. (1998). After 20 min the assay was stopped and cleared of cell debris by centrifugation (13000 r.p.m.; $10 \mathrm{~min}$ ). The release of PNP was measured spectrophotometrically at $415 \mathrm{~nm}$. Enzyme activities were calculated and expressed in nmol PNP $\mathrm{min}^{-1}$ per $\mathrm{OD}_{600}$ unit.

$\beta$-D-Galactosidase (lacZ) was assayed similarly, with $50 \mu \mathrm{l}$ $o$-nitrophenyl $\beta$-D-galactopyranoside. $o$-Nitrophenol was detected at $420 \mathrm{~nm}$.

DNA techniques. Standard DNA techniques were carried out according to Maniatis et al. (1982). Total DNA was prepared by the CTAB method described by K. Wilson in Ausubel et al. (1987). Plasmid DNA from cultures was purified with the NucleoSpin Plasmid kit (Macherey-Nagel). DNA fragments from agarose gels were isolated using the NucleoSpin Extract kit (Macherey-Nagel) according to the manufacturer's instructions.

Construction of the $\mathrm{pJP2}$ promoter-probe vector. The basis of the pJP2 promoter-probe vector is the broad-host-range, mobilizable plasmid pTR102 (Weinstein et al., 1992), a miniRK2 derivative, containing par functions ensuring plasmid stability.
First, the BamHI, Pst I and HindIII restriction sites of pTR102 were deleted by BamHI and HindIII restriction, Klenow fill-in and religation, leading to vector pTR102-d. Then a promoterless uidA gene (GUS) from pCCOGUS (Axelos et al., 1989) was cloned into the PstI and SacI sites of pTR102-d, leading to pTR102-GUS. An artificial multiple cloning site was inserted into the NcoI and KpnI sites of pTR102-GUS. Two complementary oligonucleotides with the following sequences were synthesized (MWG-Biotech) : 5'-CAT GGA TCC AAG CTT CTC GAG CTC TAG ACT GAG GTA AT-3' and 5'-CAT GAT TAC CTC AGT CTA GAG CTC GAG AAG CTT GGA TCC ATG GTA C-3' (Fig. 1b). The fragment contains a ribosome-binding sequence (GAGG, $5 \mathrm{bp}$ upstream of the ATG), which was a consensus compiled from a number of known $R$. leguminosarum fix and nif genes. Stop codons were introduced in all reading frames to prevent translational gene fusions to the GUS protein. Finally several single-cutting restriction sites were added to facilitate cloning of DNA fragments.

The resulting plasmid pJP2 (Fig. 1a) was tested for background levels of GUS activity in R. leguminosarum VF39 under freeliving conditions in TY medium and during symbiosis with the pea host plant. In both cases only negligible activities were observed, which demonstrated the absence of vector promoters reading into the uidA gene.

Sequence analyses. Appropriate restriction sites within the gabT region were used to clone $300-800 \mathrm{bp}$ fragments into vector pUC19. Sequencing of the resulting recombinant plasmids was done for both strands by the chain-termination method using a Thermo Sequenase fluorescent labelled primer cycle sequencing kit with 7-deaza-dGTP (Amersham Pharmacia Biotech) and IRD700/800 labelled standard primers (universal and reverse) according to the manufacturer's instructions. Extension products were separated and detected on a LI-COR 4200L sequencer. An IRD700-labelled IS50 
(a)

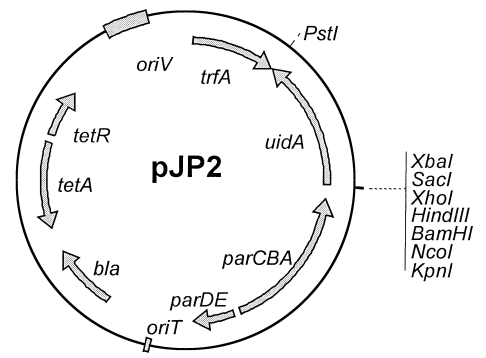

(b) $5^{\prime}$

CATGGATCCAAGCTTCTCGAGCTCTAGACTGAGGTAAT - 3' 3' -CATGGTACCTAGGTTCGAAGAGCTCGAGATCTGACTCCATTAGTAC-5'

Kpnl Ncol BamHI Hindlll Xhol Sacl Xbal
Fig. 1. Physical and genetic map of the pJP2 promoter-probe vector. (a) The vector encodes tetracycline (tetR/tet $A$ ) and ampicillin (b/a) resistance. trfA, RK2 replication initiation gene; oriV, RK2 origin of vegetative replication; oriT, RK2 origin of transfer. The parCBA and parDE operons encode genes that ensure plasmid stability in the absence of antibiotic selection. uidA, E. coli GUS gene. (b) Oligonucleotides used to introduce stop codons (bold) and single-cutting restriction sites (underlined) which were added to facilitate the cloning of DNA fragments. The ATG start codon of the GUS gene (shaded, in 3 '-direction) is part of the GTAC 5'-overhang (right side). The Ncol restriction site (right side) was not reconstituted upon cloning into pTR102-GUS.

(a)

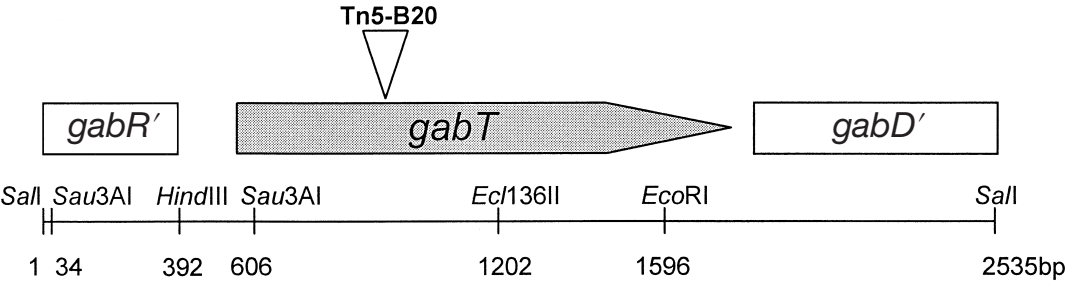

(b)

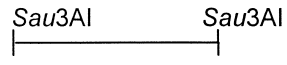

(c) Sall
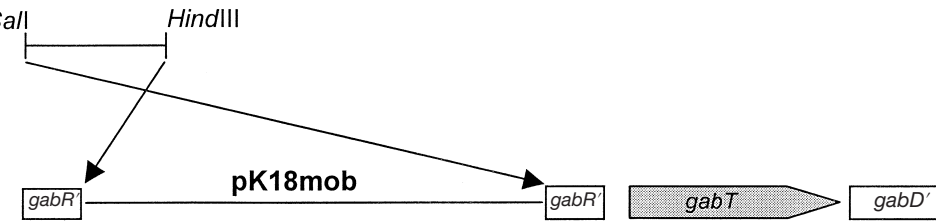

VF39-18R

(d)

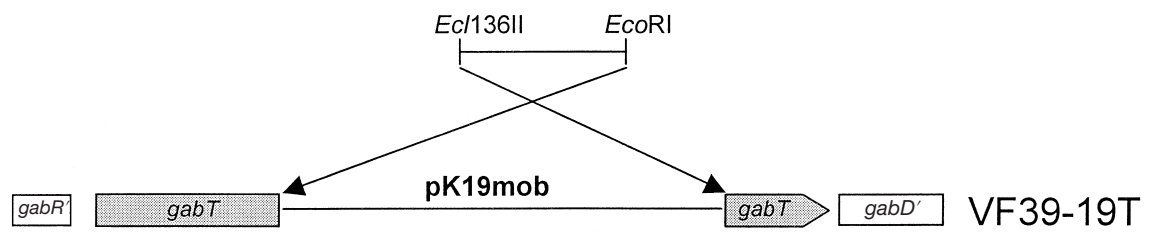

Fig. 2. Organization of the $2 \cdot 5 \mathrm{~kb}$ Sall fragment containing gabT and construction of the plasmid integration mutants VF39-18R and VF39-19T. (a) Physical and genetic map of the gabRTD region on the 2535 bp Sall fragment. The site of the Tn5-B20 insertion in mutant PH10 is marked by a triangle. Additional Sau3Al and EcoRI sites between bp 606 and 2535 are not indicated. (b) The 572 bp Sau3Al fragment was used for promoter studies in promoter-probe vector pJP2-gabT. (c) The $392 \mathrm{bp} \mathrm{Sall/HindIII} \mathrm{fragment} \mathrm{was} \mathrm{cloned} \mathrm{into} \mathrm{pK18mob} \mathrm{(pK18mob-gabR)} \mathrm{to} \mathrm{generate} \mathrm{the} \mathrm{plasmid} \mathrm{integration} \mathrm{mutant}$ VF39-18R. (d) The $394 \mathrm{bp} \mathrm{Ec/136II/EcoRI} \mathrm{fragment} \mathrm{was} \mathrm{cloned} \mathrm{into} \mathrm{pK19mob} \mathrm{(pK19mob-gabT)} \mathrm{to} \mathrm{generate} \mathrm{the} \mathrm{plasmid}$ integration mutant VF39-19T.

primer (5'-CGG GAA AGG TTC CGT TCA GGA CG-3') was used to sequence fragments flanking the Tn5-B20.

Nucleotide sequence comparisons were done by the NCBI BLAST2 package (Altschul et al., 1997) against the NCBI-nr database.

Construction of plasmid integration mutants. A $394 \mathrm{bp}$ Ecl136II/EcoRI fragment (Fig. 2d) was used for the con- struction of the gabT integration mutant VF39-19T. The fragment was cloned into the $S m a \mathrm{I} / E c o$ RI sites of pK19mob, resulting in pK19mob-gabT. The plasmid was transferred from E. coli S17-1 to R. leguminosarum VF39 and recombined into the genomic gabT region via single crossover. Total DNA of the resulting clones was digested with SalI and with EcoRI, separated by gel electrophoresis, transferred onto Qiabrane nylon membranes (Qiagen) by vacuum blotting (Pharmacia) 
and correct integration was verified by Southern hybridization at $68^{\circ} \mathrm{C}$ with a PCR-derived (using universal and reverse primers and pK19mob-gabT as template) and digoxigenin11-dUTP-labelled gabT probe (DIG DNA Labelling Kit; Boehringer). The integration mutant was designated VF3919T and used for further studies.

To generate a gabR mutant, a 392 bp SalI/HindIII fragment (Fig. 2c) was cloned into the SalI/HindIII sites of pK18mob, yielding pK18mob-gabR. After plasmid integration into the VF39 genome, the corresponding mutant VF39-18R was isolated and correct mutagenesis was tested by Southern hybridization.

Plant cultivation, thin sections and staining. The pea Pisum sativum cv. Rondo was used as a host plant in this work. Seeds were sterilized in concentrated sulphuric acid for $15 \mathrm{~min}$, washed three times with sterile water and germinated on sterile vermiculite. Five seedlings were then transferred to sterile vermiculite in $10 \times 10 \mathrm{~cm}$ plastic boxes and grown for $3 \mathrm{~d}$.

Bacteria were pre-grown on solid medium in the presence of the appropriate antibiotics. A loop of cells was resuspended in $3 \mathrm{ml}$ sterile water and used for inoculation. Plants were grown at $22{ }^{\circ} \mathrm{C}$ under artificial light for $16 \mathrm{~h}$ a day.

Nodules were harvested after $28 \mathrm{~d}$ and prepared for GUS activity assays and histochemical staining.

Bacteroid suspensions for GUS assays were prepared as follows. Five to ten fresh nodules were collected in $1 \mathrm{ml}$ $50 \mathrm{mM}$ sodium phosphate buffer $(\mathrm{pH} 7 \cdot 0)$. The nodules were crushed with an appropriately shaped metal rod. Plant tissue was removed by centrifugation (5 min; 1250 r.p.m.). The supernatant was cleared (5 min; 4500 r.p.m.) and the pellet resuspended in $500 \mu \mathrm{l}$ sodium phosphate buffer. The resulting bacteroid suspension was directly used for GUS activity assays as described above.

For thin sectioning, fresh nodules were sliced under $50 \mathrm{mM}$ sodium phosphate buffer ( $\mathrm{pH} 7 \cdot 0$ ) into $80 \mu \mathrm{m}$ sections using a Leica VT1000S vibratome. The sections were incubated in staining buffer $(50 \mathrm{mM}$ sodium phosphate buffer $\mathrm{pH} 7 \cdot 0$; $0 \cdot 1 \%$ Triton $\left.\mathrm{X}-100 ; 5 \mathrm{mM} \mathrm{K}_{3}\left[\mathrm{Fe}(\mathrm{CN})_{6}\right] ; 5 \mathrm{mM} \mathrm{K}_{4}\left[\mathrm{Fe}(\mathrm{CN})_{6}\right]\right)$ containing $0.02 \%$ X-Glc until clear blue staining appeared. For strongly expressed fusions the staining time was about 30-60 min. The reaction was stopped by fixing the sections in $1.25 \%$ glutaraldehyde in $50 \mathrm{mM}$ sodium phosphate buffer ( $\mathrm{pH} 7 \cdot 0)$. Pictures were taken on an Olympus B201 bright-field microscope.

\section{RESULTS}

\section{Cloning and identification of the $R$. leguminosarum bv. viciae VF39 GABA aminotransferase gene}

A R. leguminosarum bv. viciae VF39 derivative with reduced lacZ background activity (VF39-TP2; T. Patschkowski, RWTH-Aachen) was mutagenized with transposon Tn5-B20 (Simon et al., 1989). This transposon carries a promoterless lacZ gene at the end of the left IS50 border. Integration of the Tn5-B20 into a gene may produce a transcriptional fusion to lacZ and thus allow the expression of the interrupted gene to be studied.

In an initial approach to identify promoters and genes induced under acidic and/or alkaline conditions, about
11000 mutants were tested for growth and expression

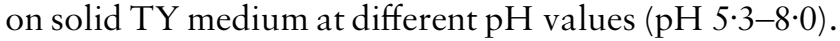
None of them was impaired in growth.

One mutant, PH10, showed a more intense blue staining on media containing X-Gal at pH 5.3 and was selected for further investigations. In liquid TY medium lacZ expression was induced twofold at $\mathrm{pH} 5 \cdot 3$ when compared with the expression level at $\mathrm{pH} 6.0$ (V. Lipka, RWTH-Aachen, unpublished).

The Tn5-B20 transposon $(8 \cdot 2 \mathrm{~kb})$ was cloned from the genome of mutant PH10 and was found to be located on a $10.7 \mathrm{~kb}$ SalI fragment (pSVB28-PH10SalI). After restriction analyses and further subcloning, the $2.5 \mathrm{~kb}$ of chromosomal DNA flanking the transposon insertion were sequenced entirely. The sequence has been deposited at the NCBI GenBank (accession no. AF335502).

An ORF encoding 426 aa interrupted by the Tn5-B20 insertion showed good homologies to several 4-aminobutyrate (GABA) aminotransferase genes and was therefore designated as gabT. The best homology was found to the Mesorhizobium loti mlr5521 gene annotated as '4-aminobutyrate aminotransferase' (Kaneko et al., 2000; NCBI accession no. NP106172), which encodes a protein $81 \%$ identical over 429 aa to the R. leguminosarum gabT gene product. The E. coli goaG gene, located on the Kohara clone \#257 at min 29.1-29.6 of the E. coli K-12 chromosome and annotated as 'GABA or ornithine aminotransferase' (Jovanovic \& Model, 1997; NCBI accession no. P50457), showed the secondbest result at the protein level, with $61 \%$ identity over $421 \mathrm{aa}$, and the third-best similarity was found with the Pseudomonas aeroginosa PAO1 gabT locus (Stover et al., 2000; NCBI accession no. AAG03655), exhibiting $57 \%$ identity over 426 aa. A second E. coli 'GABA aminotransferase' gene, located on the Kohara clone \#443 at min $59 \cdot 8-60 \cdot 2$ of the K-12 chromosome (NCBI accession no. P22256), showed the fourth-best homology. The identity was $56 \%$ over 426 aa. This gene is part of the gabCDTP region (Bartsch et al., 1990), which encodes gene products responsible for uptake (gabP) and degradation (gabDT) of GABA.

Downstream of the $R$. leguminosarum gabT gene, the $5^{\prime}$-end of another ORF was discovered, encoding a putative protein with homologies to the N-terminus of several SSDHs (data not shown); SSDH is the next enzyme in the GABA shunt pathway. This ORF was therefore designated as gabD' (Fig. 2). A third ORF identified upstream of gabT and orientated in the opposite direction showed homologies to merR-type transcriptional regulators and thus may specify a regulator for gabTD expression. It was tentatively named as gabR'.

\section{The phenotype of gabT mutants}

The R. leguminosarum PH10 Tn5-B20 mutant was tested for growth in liquid VMM containing GABA as sole carbon and nitrogen source. Growth rates of the 
Table 2. Phenotypes of $R$. leguminosarum VF39 and several mutants

\begin{tabular}{|c|c|c|c|c|}
\hline Phenotype & VF39 & PH10 & VF39-19T & VF39-18R \\
\hline Growth in liquid VMM + GABA (doubling time, $\mathrm{h}$ )* & $16 \cdot 0( \pm 1 \cdot 8)$ & $16 \cdot 0( \pm 1 \cdot 8)$ & $17 \cdot 8( \pm 0 \cdot 6)$ & $14 \cdot 3( \pm 0 \cdot 9)$ \\
\hline $\begin{array}{l}\text { 2-Oxoglutarate-dependent GABA aminotransferase } \\
\left.\text { activity [nmol glutamate } \min ^{-1}(\text { mg protein })^{-1}\right] \dagger\end{array}$ & $1 \cdot 32( \pm 0 \cdot 38)$ & $-0 \cdot 09( \pm 0 \cdot 20)$ & $0 \cdot 09( \pm 0 \cdot 15)$ & $6 \cdot 82( \pm 1 \cdot 17)$ \\
\hline $\begin{array}{l}\text { Pyruvate-dependent GABA aminotransferase activity } \\
{\left[\text { nmol alanine } \min ^{-1}(\mathrm{mg} \text { protein })^{-1}\right] \dagger}\end{array}$ & $213( \pm 33)$ & $227( \pm 27)$ & $203( \pm 22)$ & $148( \pm 17)$ \\
\hline SSDH activity $\left.\left[\mathrm{nmol} \mathrm{NADH} \mathrm{min}^{-1}(\mathrm{mg} \text { protein })^{-1}\right]\right) \dagger$ & $182( \pm 17)$ & $199( \pm 32)$ & $155( \pm 26)$ & $228( \pm 22)$ \\
\hline
\end{tabular}

*Growth rates were calculated from cultures (VMM, $0 \cdot 2 \%$ GABA) in the exponential growth phase. The data are means from three independent cultures, with SD in parentheses.

†Enzyme activities are means from four independent cultures (VMM, 0·2\% GABA + glutamate), with SD in parentheses.

mutant showed no difference from the wild-type (Table 2).

The ability of PH10 to utilize GABA as a sole carbon and nitrogen source posed the question of a second GABA aminotransferase gene in this strain. Therefore the enzyme activity of the GABA aminotransferase, using GABA as substrate and either 2-oxoglutarate or pyruvate as amino-accepting oxoacid, was tested in mutant and wild-type. Both activities could be demonstrated in the wild-type strain. The gabT mutant showed a total absence of 2-oxoglutarate-dependent GABA aminotransferase activity (Table 2), suggesting that the identified gene indeed encodes the only 2-oxoglutaratedependent GABA aminotransferase in $R$. leguminosarum VF39. Pyruvate-dependent GABA aminotransferase activity, however, was not affected by the gabT mutation. This demonstrates the existence of a second gene encoding a pyruvate-dependent GABA aminotransferase with no 2-oxoglutarate-dependent activity.

To confirm that the absence of 2-oxoglutarate-dependent GABA aminotransferase from the PH10 extracts was indeed due to the mutation in the gabT gene, a plasmid integration mutant (VF39-19T) was generated. This mutant showed the same phenotypes as the PH10 strain.

To see if the downstream gabD gene is similarly affected by the gabT mutation, SSDH activity was also measured. The wild-type strain and all mutants showed similar SSDH levels (Table 2).

In symbiosis with the host $P$. sativum both gabT mutants produced normal, pink nodules and showed nitrogen fixation activities comparable to the wild-type.

\section{Free-living and symbiotic expression of gabT}

To study gabT regulation, a 572 bp Sau3AI fragment (Fig. $2 \mathrm{~b}$ ) containing the putative gabT promoter region was cloned into the BamHI site of the promoter-probe vector pJP2. The Sau3AI fragment contains the complete intergenic region between gabT and the predicted gabR' gene. It also includes 77 nucleotides of the $5^{\prime}$-end of the gabT coding region.
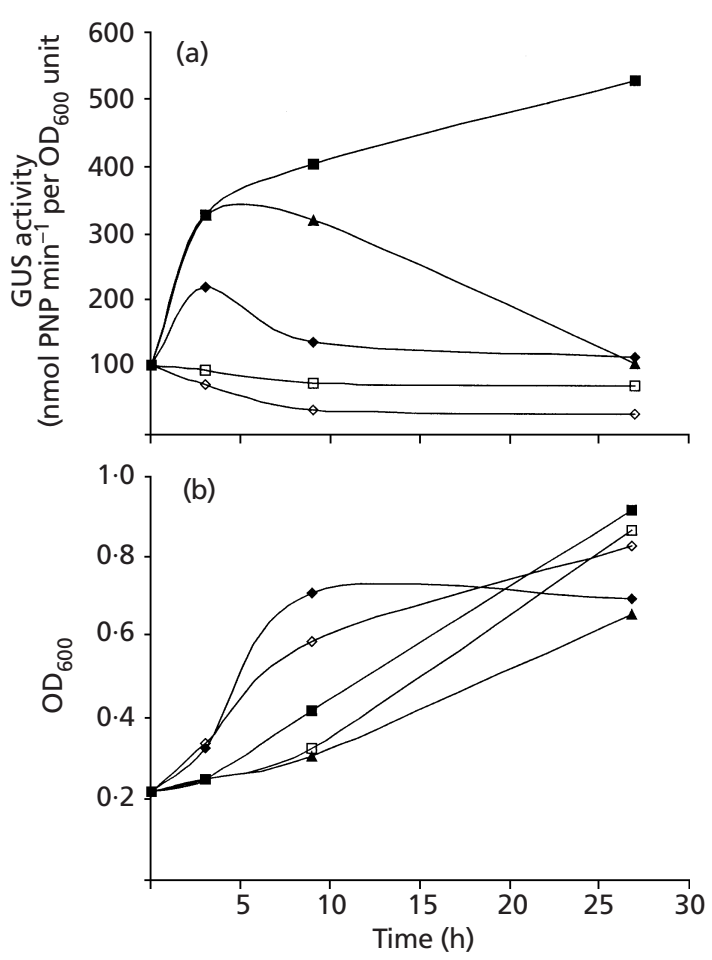

Fig. 3. Induction of the gabT promoter in wild-type VF39. (a) GUS activity was monitored over a period of $27 \mathrm{~h}$ in liquid cultures (VMM, $0.2 \%$ of different carbon and nitrogen sources: $\Delta$, GABA; $\square$, GABA + glutamate; $\diamond$, GABA + succinate; $\square$, glutamate; $\diamond$, succinate +ammonium). (b) Corresponding growth curves. Data are means from three independent cultures. Standard deviation never exceeded $16 \%$ of the mean.

The fusion plasmid pJP2-gabT was transferred into $R$. leguminosarum VF39 and the induction of the gabT promoter was monitored during growth on different carbon and nitrogen sources. As shown in Fig. 3, GABA, as the substrate for the GABA aminotransferase, induces transcription of gabT, although only transiently. An initial threefold induction was observed, which declined to the basal level within $24 \mathrm{~h}$. Glutamate, which is thought to be an intermediate in the GABA shunt pathway and a possible precursor of GABA, did not 
induce the gabT promoter and neither did succinate, the end-product of the pathway. Succinate, however, caused a reduction of the basal level of transcriptional activity.

Putrescine, which has a structural similarity to GABA, was also found to induce the gabT promoter, but it did not support growth as a sole carbon source (data not shown). Ornithine, as a possible precursor of putrescine, or as an alternative substrate for the aminotransferase, supported good growth, but did not mediate induction of the gabT:: uidA gene fusion (data not shown).

The effect of dual carbon sources was also examined. In combination with GABA, glutamate led to prolonged expression of gabT (Fig. 3), compared to the transient expression with GABA alone. Succinate in combination with GABA decreased the induction seen with GABA alone.

The expression of the gabT promoter was also studied during symbiosis with pea as a host plant. It was found to be induced in the proximal part of the infection zone (II), next to interzone II-III, and strongly expressed in the late symbiotic zone (results not shown). The symbiotic activity of the gabT::uidA fusion was $813 \pm 63$ nmol PNP min $^{-1}$ per $\mathrm{OD}_{600}$ unit (mean $\pm \mathrm{sD} ; n$ $=3$ ), which is comparable to the magnitude of maximum free-living induction by GABA and glutamate (Fig. 3).

\section{Role of gabR in gabT expression}

To investigate a possible function of GabR in gabT regulation, a plasmid integration mutant of gabR (VF39$18 \mathrm{R}$ ) was constructed (see Methods). When pJP2-gabT was introduced into this mutant derivative, deep blue colonies were formed on TY plates containing X-Glc, while the wild-type carrying this plasmid produced only slightly bluish colonies after several days of growth. Quantitative measurements of GUS activity confirmed a constitutively high activity of the gabT gene fusion in the gabR mutant background. Overnight cultures in liquid TY medium resulted in GUS activities of about 700 nmol PNP min $^{-1}$ per OD $_{600}$ unit, whereas the wildtype showed only about $100 \mathrm{nmol} P N P \min ^{-1}$ per $\mathrm{OD}_{600}$ unit (Fig. $3 ; t=0$ ). Consistent with this, 2-oxoglutaratedependent GABA aminotransferase activity in protein extracts from the mutant was about five times higher than in the wild-type (Table 2). These results indicate that gabT expression is significantly enhanced in a $g a b R$ mutant background and that GabR acts as a repressor modulating gabT transcription.

When tested for growth in VMM liquid medium containing GABA as a sole nitrogen and carbon source, the gabR mutant VF39-18R showed no difference from the wild-type or the gabT mutants (Table 2).

\section{DISCUSSION}

In this work we have identified and characterized the gabT gene from R. leguminosarum bv. viciae VF39. The gabT gene encodes an 2-oxoglutarate-dependent GABA aminotransferase, an enzyme of the GABA shunt pathway, which is a theoretical bypass for the 2-oxoglutarate dehydrogenase complex. Although homology comparisons with the $R$. leguminosarum gabT sequence revealed several putative GABA aminotransferases in the databases, published work on the genes and mutants in bacteria is rare. Except for the gabT gene of E. coli K12 (Bartsch et al., 1990), most of the data encountered are annotations from various genome projects. This is the first report of a well-characterized mutant in one of the GABA shunt enzymes in the genus Rhizobium.

E. coli K-12 wild-type strains (CS101A and CS8A) have been found to be unable to grow on GABA as a sole source of carbon and nitrogen (Dover \& Halpern, 1971). However, UV-induced mutants are able to use GABA as a sole nitrogen source, and in these mutants GABA aminotransferase and SSDH activity were both increased six- to ninefold. These mutants were proposed to be regulatory mutants. A second generation of UVinduced mutations permitted growth on GABA as sole source of carbon and nitrogen (Dover \& Halpern, 1971), and led to increased uptake of GABA. These results indicate that in E. coli K-12 the GABA shunt can serve as a metabolic pathway for GABA degradation.

In contrast to E. coli, R. leguminosarum bv. viciae VF39 grows on GABA as a sole source of carbon and nitrogen. The gabT mutants are not impaired in growth on GABA even though the activity of 2-oxoglutarate-dependent GABA aminotransferase is absent. However, pyruvatedependent GABA aminotransferase activity is unaffected by the gabT mutation and may be responsible for continued growth on GABA. This implicates the presence of at least two genes encoding GABA aminotransferases with distinct substrate specificities in $R$. leguminosarum bv. viciae.

Enzyme activities of 2-oxoglutarate and pyruvate-dependent GABA aminotransferase were earlier presented from Sinorhizobium meliloti bacteroids by Miller et al. (1991) and from Bradyrhizobium japonicum bacteroids by Kouchi et al. (1991). The question of whether one or two enzymes were responsible for the different activities was not solved in these reports.

The pyruvate-dependent GABA aminotransferase activity in the gabT mutants of $R$. leguminosarum VF39 maintains a functioning GABA shunt pathway. The GABA shunt has often been discussed to play a role in rhizobial carbon metabolism during symbiosis, as the 2oxoglutarate dehydrogenase complex is thought to be inhibited by excess of reducing equivalents under the oxygen-limiting conditions present in the nodule (McDermott et al., 1989; Vance \& Heichel, 1991; Dunn, 1998; Poole \& Allaway, 2000).

Miller et al. (1991) reported relatively high GABA concentrations $\left[31 \mathrm{nmol}\left(\mathrm{mg}\right.\right.$ protein) $\left.{ }^{-1}\right]$ in bacteroids of S. meliloti. Similarly, Vance \& Heichel (1991) found GABA to be present in whole root nodules at concentrations of about $400-8000 \mathrm{nmol}(\mathrm{g} \text { fresh wt })^{-1}$. They further discussed a role for GABA in regulation of 
cytoplasmic $\mathrm{pH}$ during microaerobic and anaerobic conditions. Assuming that $\mathrm{HCO}_{3}^{-}$serves as a substrate for nodule PEP carboxylase, acidosis resulting in excess $\mathrm{H}^{+}$produced during hydration of dark $\mathrm{CO}_{2}$ fixation could be toxic to host cells. Decarboxylation of glutamate to GABA could therefore be a significant sink for protons. This could explain why the gabT transposon mutant described here was initially identified by a screen for genes induced at low $\mathrm{pH}$ values.

To investigate gabT expression in $R$. leguminosarum bv. viciae during symbiosis, we constructed a new promoter-probe vector $\mathrm{pJP2}$, which is maintained stably even in the absence of selective pressure. Vector stability is traditionally tested via re-isolation of rhizobia from crushed nodules and plating on selective media (Weinstein et al., 1992; Dombrecht et al., 2001). However, for $S$. meliloti the differentiation from free-living bacteria to bacteroids is irreversible and bacteroids do not regenerate viable cells on growth medium (McRae et al., 1989). Re-isolation from crushed nodules only results in growth of free-living or transforming bacteria but not bacteroids. We therefore believe that plasmid loss can be best visualized in stained thin sections of whole nodules, and it was never observed in the case of $\mathrm{pJP} 2$.

In pea nodules, the $R$. leguminosarum VF39 gabT promoter is induced directly before interzone II-III, and the gene is highly expressed throughout the late symbiotic zone III. This suggests a role of the GABA aminotransferase in the metabolism of the bacteroids. During symbiosis with the pea host, however, gabT mutants (PH10 and VF39-19T) did not show any phenotypes distinctly different from VF39. Also, expression of the gabT: : uidA fusion in the mutant VF39$19 \mathrm{~T}$ was not affected on the plant (data not shown).

To evaluate the possible role of the GABA shunt in bacteroid metabolism, a double mutant in both GABA aminotransferases may be required. Therefore a gabT deletion mutant is now being used as a recipient in a second transposon mutagenesis. Screening for mutants unable to grow on GABA may lead to a strain affected in pyruvate-dependent GABA aminotransferase activity.

\section{ACKNOWLEDGEMENTS}

We thank Volker Lipka for isolating the PH10 mutant and Laura Green for her kind and helpful advice on performing the SSDH assay. This work was partly funded by the INCO-DC programme of the European Community (contract no. IC18CT980313) and the ARC-program of the DAAD (Aktenzeichen 393-ARC-XIV).

\section{REFERENCES}

Allaway, D., Lodwig, E., Crompton, L. A., Wood, M., Parsons, R., Wheeler, T. R. \& Poole, P. S. (2000). Identification of alanine dehydrogenase and its role in mixed secretion of ammonium and alanine by pea bacteroids. Mol Microbiol 36, 508-515.

Altschul, S. F., Madden, T. L., Schäffer, A. A., Zhang, J., Zhang, Z., Miller, W. \& Lipman, D. J. (1997). Gapped BLAST and PSI-BLAST : a new generation of protein database search programs. Nucleic Acids Res 25, 3389-3402.

Arnold, W. \& Pühler, A. (1988). A family of high-copy-number plasmid vectors with single end-label sites for rapid nucleotide sequencing. Gene 70, 171-179.

Ausubel, F. M., Brent, R. \& Kingston, R. (editors) (1987). Current Protocols in Molecular Biology. New York: Wiley.

Axelos, M., Bardet, C., Liboz, T., Le Van Thai, A., Curie, C. \& Lescure, B. (1989). The gene family encoding the Arabidopsis thaliana translational elongation factor EF-1 $\alpha$ : molecular cloning, characterisation and expression. Mol Gen Genet 219, 106-112.

Bartsch, K., von Johnn-Marteville, A. \& Schulz, A. (1990). Molecular analysis of two genes of the Escherichia coli gab cluster: nucleotide sequence of the glutamate:succinic semialdehyde transaminase gene (gabT) and characterization of the succinic semialdehyde dehydrogenase gene (gabD). J Bacteriol 172, 7035-7042.

Beringer, J. E. (1974). R factor transfer in Rhizobium leguminosarum. J Gen Microbiol 84, 188-198.

Bradford, M. M. (1976). A rapid and sensitive method for the quantitation of microgram quantities of protein utilizing the principle of protein-dye binding. Anal Biochem 72, 248-254.

Boesten, B., Batut, J. \& Boistard, P. (1998). DctBD-dependent and -independent expression of the Sinorhizobium (Rhizobium) meliloti $\mathrm{C}_{4}$-dicarboxylate transport gene $(\operatorname{dct} A)$ during symbiosis. Mol Plant-Microbe Interact 11, 878-886.

Colonna-Romano, S., Arnold, W., Schlüter, A., Boistard, P., Pühler, A. \& Priefer, U. B. (1990). An Fnr-like protein encoded in Rhizobium leguminosarum bv. viciae shows structural and functional homology to Rhizobium meliloti FixK. Mol Gen Genet 223, 138-147.

Dombrecht, B., Vanderleyden, J. \& Michiels, J. (2001). Stable RK2derived cloning vectors for the analysis of gene expression and gene function in gram-negative bacteria. Mol Plant-Microbe Interact 14, 426-430.

Dover, S. \& Halpern, Y. S. (1971). Utilisation of $\gamma$-aminobutyric acid as sole carbon and nitrogen source by Escherichia coli K-12 mutants. J Bacteriol 109, 835-843.

Dunn, M. F. (1998). Tricarboxylic acid cycle and anapleurotic enzymes in Rhizobia. FEMS Microbiol Rev 22, 105-123.

Jovanovic, G. \& Model, P. (1997). PspF and IHF bind cooperatively in the $p s p$ promoter-regulatory region of Escherichia coli. Mol Microbiol 25, 473-481.

Kaneko, T., Nakamura, Y., Sato, S. \& 21 other authors (2000). Complete genome structure of the nitrogen-fixing symbiotic bacterium Mesorhizobium loti (supplement). DNA Res 7, 381-406.

Kouchi, H., Fukai, K. \& Kihara, A. (1991). Metabolism of glutamate and aspartate in bacteroids isolated from soybean root nodules. $J$ Gen Microbiol 137, 2901-2910.

Maniatis, T., Fritsch, E. F. \& Sambrook, J. (1982). Molecular Cloning: a Laboratory Manual. Cold Spring Harbor, NY: Cold Spring Harbor Laboratory.

McDermott, T. R., Griffith, S. M., Vance, C. P. \& Graham, P. H. (1989). Carbon metabolism in Bradyrhizobium japonicum bacteroids. FEMS Microbiol Lett 63, 327-340.

McRae, D. G., Miller, R. W. \& Berndt, W. B. (1989). Viability of alfalfa nodule bacteroids isolated by density gradient centrifugation. Symbiosis 7, 67-80.

Miller, R. W., McRae, D. G. \& Joy, K. (1991). Glutamate and 
gamma-aminobutyrate metabolism in isolated Rhizobium meliloti bacteroids. Mol Plant-Microbe Interact 4, 37-45.

Poole, P. S. \& Allaway, D. (2000). Carbon and nitrogen metabolism in Rhizobium. Adv Microb Physiol 43, 117-163.

Poole, P. S., Blyth, A., Reid, C. J. \& Walters, K. (1994). myoInositol catabolism and catabolite regulation in Rhizobium leguminosarum bv. viciae. Microbiology 140, 2787-2795.

Priefer, U. B. (1989). Genes involved in lipopolysaccharide production and symbiosis are clustered on the chromosome of Rhizobium leguminosarum bv. viciae VF39. J Bacteriol 171, 6161-6168.

Salminen, S. O. \& Streeter, J. G. (1992). Labelling of carbon pools in Bradyrhizobium japonicum and Rhizobium leguminosarum bv. viciae bacteroids following incubation of intact nodules with ${ }^{14} \mathrm{CO}_{2}$. Plant Physiol 100, 597-604.

Schäfer, A., Tauch, A., Jäger, W., Kalinowski, J., Thierbach, G. \& Pühler, A. (1994). Small mobilizable multi-purpose cloning vectors derived from the Escherichia coli plasmids pK18 and pK19: selection of defined deletions in the chromosome of Corynebacterium glutamicum. Gene 145, 69-73.

Simon, R., Priefer, U. B. \& Pühler, A. (1983). A broad host range mobilization system for in vivo genetic engineering: transposon mutagenesis in Gram negative bacteria. Bio/Technology 1, 784-791.

Simon, R., Quandt, J. \& Klipp, W. (1989). New derivatives of transposon Tn5 suitable for mobilization of replicons, generation of operon fusions and induction of genes in Gram-negative bacteria. Gene 80, 161-169.
Stover, C. K., Pham, X. Q., Erwin, A. L. \& 23 other authors (2000). Complete genome sequence of Pseudomonas aeruginosa PAO1, an opportunistic pathogen. Nature 406, 959-964.

Streeter, J. G. (1991). Transport and metabolism of carbon and nitrogen in legume nodules. Adv Bot Res Incorp Adv Plant Pathol $18,129-187$.

Vance, C. P. \& Heichel, G. H. (1991). Carbon in $\mathrm{N}_{2}$ fixation: limitation or exquisite adaptation. Annu Rev Plant Physiol Plant Mol Biol 42, 373-392.

Vincent, J. M. (1970). A Manual for the Practical Study of Root Nodule Bacteria. Oxford: Blackwell Scientific.

Walshaw, D. L., Wilkinson, A., Mundy, M., Smith, M. \& Poole, P. S. (1997). Regulation of the TCA cycle and the general amino acid permease by overflow metabolism in Rhizobium leguminosarum. Microbiology 143, 2209-2221.

Waters, J. K., Hughes, B. L., Purcell, L. C., Gerhardt, K. O., Mawhinney, T. P. \& Emerich, D. W. (1998). Alanine, not ammonia, is excreted from $\mathrm{N}_{2}$-fixing soybean nodule bacteroids. Proc Natl Acad Sci U S A 95, 12038-12042.

Weinstein, M., Roberts, R. C. \& Helinski, D. R. (1992). A region of the broad-host-range plasmid RK2 causes stable in planta inheritance of plasmids in Rhizobium meliloti cells isolated from alfalfa root nodules. J Bacteriol 174, 7486-7489.

Received 16 July 2001; revised 3 October 2001; accepted 18 October 2001. 